\section{New safeguarding advice for dental teams}

Dental professionals have been reminded of the importance of making sure practices are fully trained and ready to deal with any issues of safeguarding of vulnerable adults and children in newly issued guidance.

Public Health England (PHE) has issued Safeguarding in general dental practice, ${ }^{1}$ which provides an overview on the roles and responsibilities of everyone in the dental team in relation to vulnerable adults and children.

The Dental Defence Union (DDU) has highlighted the guidance, stressing that dental professionals have an existing 'ethical and legal duty' to act if they believe a patient is being abused, and in this highly sensitive area it helps to be aware of relevant guidance and available support.

The new PHE guidance sets out steps to follow in cases of suspected abuse and defines common terminology and different categories of abuse, sets out the legal and regulatory

framework, and provides information about training and other resources.

It includes various recommendations for all dental practices to ensure they have proper safeguarding arrangements in place, including:

- Have a practice safeguarding policy that sets out the practice's commitment to protect children and vulnerable patients which should then be regularly reviewed

- Have a named safeguarding practice lead to ensure staff undertake appropriate training and have access to support and advice

- Organise ongoing safeguarding training for both clinical and non-clinical staff that is appropriate for their role

- Have a safeguarding reporting system in place that is known to staff

- Incorporate Safeguarding in general dental practice as part of the staff induction process to supplement existing safeguarding training

- Discuss the guidance at team meetings and consider how training opportunities and resources can be embedded into the practice.

A section of the guidance is devoted to confidentiality, consent and informationsharing in safeguarding cases, which the DDU said was a subject that sometimes prompted calls to its advice line.

David Lauder, Dento-Legal Adviser for the DDU, said: 'It makes clear that dental professionals duty of patient confidentiality is, "not intended to prevent exchange of information between different professionals and staff who have a responsibility for ensuring the protection of children, young people and adults at risk".

'If you're not sure whether safeguarding concerns justify the disclosure of confidential information, the guidance recommends getting advice from the relevant local safeguarding contact. The DDU is also a good source of support and advice for members.

'In the absence of consent, practices should get advice from their local safeguarding contact or the DDU. Sharing information with the appropriate agencies without consent may be justified if the disclosure is in the patient's best interests or is necessary to protect others from a risk of serious harm.'

The DDU recommended members kept a record of their decision and the reasons for it - whether it was to share information or not, what information has been shared, with whom and for what purpose.

\section{References}

1. Public Health England. Safeguarding in general dental practice. 3 April 2019. Available at: https://www.gov.uk/ government/publications/safeguarding-ingeneral-dental-practice (accessed April 2019).

\title{
CHILD ORAL HEALTH SCHEME NATIONAL AWARD ANNOUNCED
}

Dental practices are being invited to enter a national competition that recognises success in increasing the number of children aged 0 to 2 years who are accessing dental care.

England's Chief Dental Officer Sara Hurley announced the launch of the 2019 NASDAL Dental Check by One Practice of the Year award at the recent NASDAL (National Association of Specialist Dental Accountants and Lawyers) biannual conference held at Acton Trussell near Stafford, on 25 April 2019.

The award recognises a practice that has successfully introduced the British Society of Paediatric Dentistry (BSPD) Dental Check by One (DCbyl) scheme into their practice.

Established in 2018, the award highlights excellence in the provision of oral care and prevention in children and showcases the opportunity to achieve a real business improvement. Last year's winner was the Maltings Dental Practice in Lincoln.

NASDAL said particular credit would be given to applications from dental practices with evidence supporting their contribution to the overall health of their community.

Sara Hurley said: 'I am delighted to endorse such a worthwhile award. The UK-wide Dental Check by One campaign was launched by BSPD in partnership with the Office of the Chief Dental Officer England (OCDO) and we are strong supporters of the initiative and early attendance. I look forward to hearing how the entrants have reached out to their communities and engaged with families.'
Liz Roebuck, President of the BSPD, welcomed the announcement of the 2019 award, saying: 'When DCbyl was first launched, we were convinced that it would be highly rewarding for the practices that committed to it.

'Our expectations were exceeded with the entries for the 2018 NASDAL DCbyl Practice of the Year Award. We are delighted to continue our support for the award and look forward to reading more inspiring entries in 2019:

All entries have to be submitted before 5pm, Friday 30 August 2019.

The winning practice will win $£ 1,000$, a trophy, and the right to use the NASDAL Dental Check by One Practice of the Year 2019 title.

More details and how to enter for the award are available by visiting https:// www.nasdal.org.uk/award/index.php. 